Research Article

\title{
Association of Apolipoprotein E Gene Polymorphism with Lipid Profile and Ischemic Stroke Risk in Type 2 Diabetes Mellitus Patients
}

\author{
Ni Putu Tesi Maratni (D), ${ }^{1}$ Made Ratna Saraswati $\left(D,{ }^{2}\right.$ Ni Nyoman Ayu Dewi, ${ }^{3}$ \\ I Wayan Putu Sutirta Yasa, ${ }^{4}$ I Putu Eka Widyadharma $\left(\mathbb{D},{ }^{5}\right.$ Ida Bagus Kusuma Putra $\mathbb{D}^{5},{ }^{5}$ \\ and Ketut Suastika $\mathbb{( D}^{2}$ \\ ${ }^{1}$ Doctoral Program of Medical Sciences, Faculty of Medicine, Udayana University, Bali, Indonesia \\ ${ }^{2}$ Department of Internal Medicine, Faculty of Medicine, Udayana University, Sanglah General Hospital, Bali, Indonesia \\ ${ }^{3}$ Department of Biochemistry, Faculty of Medicine, Udayana University, Bali, Indonesia \\ ${ }^{4}$ Department of Clinical Pathology, Faculty of Medicine, Udayana University, Sanglah General Hospital, Bali, Indonesia \\ ${ }^{5}$ Department of Neurology, Faculty of Medicine, Udayana University, Sanglah General Hospital, Bali, Indonesia
}

Correspondence should be addressed to Ketut Suastika; ksuas@unud.ac.id

Received 17 January 2021; Revised 15 March 2021; Accepted 17 March 2021; Published 26 March 2021

Academic Editor: Roxana Valdés-Ramos

Copyright (c) $2021 \mathrm{Ni}$ Putu Tesi Maratni et al. This is an open access article distributed under the Creative Commons Attribution License, which permits unrestricted use, distribution, and reproduction in any medium, provided the original work is properly cited.

\begin{abstract}
Background. Altered lipid profiles have consistently been linked to cerebrovascular events. Ischemic stroke (IS) was a common comorbid condition established in type 2 diabetes mellitus (T2DM). The apolipoprotein E (ApoE) gene which has a notably critical function in lipoprotein metabolism is believed as one of the potential candidate genes susceptible to IS complications in T2DM. This research aimed to determine the association of apolipoprotein E gene polymorphism with lipid profile and IS risk in T2DM patients. Methods. This case-control study involved a total of 60 diabetic participants divided into two groups with and without IS. ApoE was genotyped using PCR and sequencing analysis. Results. The most predominant genotype observed in 27 participants (45\%) was E3/E3. Lower levels of high-density lipoprotein cholesterol (HDL-C) were found in $\varepsilon 2$ carriers ( $p=0.003$; 95\% CI $-23.35-4.89$ ) and $\varepsilon 4$ carriers ( $p=0.019$; 95\% CI 1.38-14.55) compared to $\varepsilon 3$ homozygotes. Total cholesterol (TC), triglyceride, and low-density lipoprotein cholesterol (LDL-C) levels had no association with ApoE gene polymorphism in this study. ApoE gene polymorphism was not related to IS in T2DM ( $p=0.06$; adjusted OR: 4.71; 95\% CI 0.93-23.79). Conclusions. ApoE $\varepsilon 2$ and $\varepsilon 4$ carriers were associated with lower levels of HDL-C. No association was identified between ApoE gene polymorphism and IS in T2DM patients.
\end{abstract}

\section{Introduction}

Type 2 diabetes mellitus (T2DM) is a complicated endocrine and metabolic disease, in which chronic hyperglycemia is provoked by peripheral insulin resistance and impaired release of insulin [1]. With the growing prevalence of overweight and obesity, concern has risen about an upsurge in the T2DM epidemic globally at an alarming rate [2]. The International Diabetes Federation (IDF) predicted that in 2017 about 425 million people worldwide have diabetes
(8.8\% of the adult population aged $20-79$ years) and about 352.1 million people $(7.3 \%)$ experience impaired glucose tolerance (IGT). By 2045, these figures are estimated to increase to around 629 million and 587 million, respectively. About $79 \%$ of diabetic patients live in countries with low to medium incomes. Indonesia is the sixth country with the greatest diabetes prevalence in the world, affecting around 10.3 million people in 2017 [3].

Long-term complications of T2DM, including microvascular and macrovascular diseases, are responsible as 
major sources of morbidity and mortality [4]. In addition to the increased diabetic nephropathy, neuropathy, and retinopathy, diabetes is also associated with stroke. T2DM patients have a fourfold greater chance of stroke compared to nondiabetic subjects [5]. Diabetic condition is also a major comorbidity factor that increases the recurrence and mortality rate from acute ischemic stroke (IS) [6]. Dyslipidemia may aggravate and promote atherosclerotic cerebral infarction in addition to the other risk factors like diabetes, hypertension, smoking habits, and family history of having cerebral infarction [7].

Apolipoprotein E (ApoE) gene and its proteins have an essential function in lipid metabolism and lipoprotein homeostasis [8]. ApoE is involved in the mechanism of facilitating the transport of triglycerides, phospholipids, cholesterol, and cholesterol esters across cells by intervening in the attachment and internalization processes of lipoprotein particles [9]. ApoE gene, mapped to chromosome 19 , is noted to have a polymorphism comprising three main alleles: $\varepsilon 2, \varepsilon 3$, and $\varepsilon 4$ and six distinct genotypes: E2/E2, E2/ E3, E2/E4, E3/E3, E3/E4, and E4/E4 [10, 11].

ApoE gene polymorphism was established to be related to plasma lipid concentrations. The $\varepsilon 2$ allele was linked with lower cholesterol levels and a lower possibility of having coronary heart disease, whereas the $\varepsilon 4$ allele had a greater risk $[12,13]$. The relation between polymorphism of the ApoE gene and stroke, however, remains uncertain. Many published articles reported about ApoE gene polymorphism involvement in stroke, but there were still conflicting results. ApoE $\varepsilon 4$ allele is referred to as a predisposing factor for cerebral infarction [14-16] and increases the risk for different stroke subtypes (IS, intracerebral and subarachnoid hemorrhage) [17]. Contradictory results stated that no relationship was discovered between ApoE gene polymorphism and stroke [18-20]. In the current study, we intended to explore the association between ApoE gene polymorphism and plasma lipid parameters and the risk of having IS in T2DM as well.

\section{Materials and Methods}

2.1. Study Participants. The participants registered in this case-control study were recruited from the Diabetes Center Outpatients Clinic and Neurology Outpatients Clinic of Sanglah General Hospital. The study was conducted from February 1, 2020, to June 11, 2020. Before participation, a written informed consent was received from each patient. The Ethics Committee of the Faculty of Medicine in Udayana University approved the study protocol (138/ UN14.2.2.VII.14/LP/2020). Enrolled subjects were grouped into two classes:

T2DM patients without IS included 30 patients diagnosed with T2DM as per the World Health Organization (WHO) criteria of fasting plasma glucose $\geq 126 \mathrm{mg} / \mathrm{dL}$ or 2-hour plasma glucose $\geq 200 \mathrm{mg} / \mathrm{dL}$ [21] or under oral diabetes medication and/or insulin.

T2DM patients complicated with IS included 30 subjects who fulfilled the WHO diagnostic criteria for diabetes or taking antidiabetic medication and complicated with IS.
Diagnosis of IS was determined by symptoms and signs of focal neurological deficit arose from a vascular occlusive lesion with an abrupt onset and symptoms lasting longer than 24 hours and confirmed using noncontrast brain CT [22].

Both sexes and participants aged $30-78$ years were included. Patients with any known renal disease, hepatic disease, malignancies, and autoimmune disease were excluded from this research. Physical and clinical data about age, sex, body mass index (BMI), blood pressure, diabetes duration, and smoking habits were recorded. Hypertension was determined by systolic blood pressure (SBP) $\geq 140 \mathrm{mmHg}$ or diastolic blood pressure (DBP) $\geq 90 \mathrm{mmHg}$ or taking antihypertensive drugs. Dyslipidemia was determined if either of the subsequent criteria is met: total cholesterol (TC) $>200 \mathrm{mg} / \mathrm{dL}$; triglycerides (TG) $>150 \mathrm{mg} / \mathrm{dL}$; low-density lipoprotein cholesterol (LDL-C) $>130 \mathrm{mg} / \mathrm{dL}$; and high-density lipoprotein cholesterol (HDL-C) $<40 \mathrm{mg} / \mathrm{dL}$ [23].

2.2. Biochemical Analysis. After 12 hours of fasting, peripheral blood samples from studied participants were obtained in the morning. Fasting plasma glucose (FPG), hemoglobin A1C (HbA1C), TC, TG, LDL-C, and HDL-C were assayed on Cobas C501 autoanalyzer (Roche Diagnostics, Germany).

2.3. Apolipoprotein E Genotyping. Genomic DNA was isolated from peripheral blood using the GeneJET Genomic DNA Purification Kit (Thermo Fisher Scientific, USA) under the manufacturer's protocol. Amplification of the ApoE target sequences was performed by polymerase chain reaction (PCR) in the Veriti 96-Well Thermal Cycler (Applied Biosystems, USA). The forward and reverse primers used were $5^{\prime}$-TCCAAGGAGCTGCAGGCGGCGCA-3' and $5^{\prime}$-GCCCCGGCCTGGTACACTGCCA-3', respectively [24]. PCR was carried out: initial denaturation at $94^{\circ} \mathrm{C}$ for $5 \mathrm{~min}$, followed by 40 cycles of denaturation at $94^{\circ} \mathrm{C}$ for $0.5 \mathrm{~min}$, annealing at $69^{\circ} \mathrm{C}$ for $0.5 \mathrm{~min}$, and extension at $70^{\circ} \mathrm{C}$ for $1.5 \mathrm{~min}$, and also a final extension at $70^{\circ} \mathrm{C}$ for $10 \mathrm{~min}$. Visualization of amplified PCR products was performed using gel electrophoresis in $0.8 \%$ agarose gel with FloroSafe DNA stain (First Base Laboratories, Malaysia). PCR products from these samples and single forward primer were sent to PT Genetika Science Indonesia (Banten, Indonesia) for DNA sequencing performed by ABI PRISM 3730xl DNA Sequencer (Applied Biosystems, USA).

2.4. Statistical Analysis. The collected data were evaluated using the Statistical Package for the Social Sciences version 17.0 application. The normality of data distribution was assessed by the Kolmogorov-Smirnov test. Numerical data were presented as mean value \pm standard deviation (SD) for normally distributed data or median (interquartile range) for data followed a nonnormal distribution. Student's $t$-test or Mann-Whitney test was carried out to compare 2 groups. ANOVA test or Kruskal-Wallis test was used for more than 
2 groups. Frequency and proportion were estimated for categorical variables and then tested by Chi-square test or Fisher's exact test. Multivariate logistic regression analysis was used to identify the association between disease and risk factors and expressed as adjusted odds ratio (OR). A statistically significant association is determined if $p$-value $<0.05$.

\section{Results}

3.1. Participants' Demographic Data. Participants' demographic and clinical data are provided in Table 1. The study involved 60 subjects classified into two categories which were T2DM complicated with IS $(n=30)$ and T2DM without complication $(n=30)$. Diabetic patients with IS had a higher level of SBP and DBP when compared to T2DM patients without complication (both $p=0.001$ ). A higher proportion of hypertension and smoking habits were found in T2DM with IS group compared to T2DM only patients ( $p=0.002$ and $p=0.008$, respectively). T2DM + IS group had a lower level of 2-hour plasma glucose compared to the T2DM group $(p<0.001)$. Significantly higher levels of TC ( $p=0.027)$ and LDL-C $(p=0.005)$ were observed among diabetic patients with IS than the T2DM group.

\subsection{Genotype and Allele Frequencies of Apolipoprotein E.} The amplified DNA fragments had 218 bp that range across both ApoE polymorphic sites (rs429358 and rs7412). All ApoE genotypes results determined by sequencing analysis are depicted in Figure 1, with ApoE genotype and allele frequencies presented in Table 2.

In the total sample, E2/E3 genotype was 8 (13.3\%), E2/E4 was 3 (5\%), E3/E3 was 27 (45\%), E3/E4 was 19 (31.7\%), and $\mathrm{E} 4 / \mathrm{E} 4$ was 3 (5\%). Genotypes distribution based on the presence of IS complication among T2DM patients did not differ significantly between the two groups $(p=0.382)$. ApoE allelic frequencies were found within the Hardy-Weinberg equilibrium in two groups. Overall, $\varepsilon 2, \varepsilon 3$, and $\varepsilon 4$ alleles frequencies were $11(9.2 \%), 81$ (67.5\%), and 28 (23.3\%), respectively. No significant allele frequency difference was established between T2DM patients with and without IS $(p=0.182)$.

\subsection{Apolipoprotein E Gene Polymorphism and Lipid} Parameters. ApoE genotypes were then classified aiming to see the relationship of ApoE gene polymorphism with lipid levels. ApoE genotypes were subdivided into three classifications, namely, $\varepsilon 2$ carriers (E2/E2 and E2/E3), $\varepsilon 3$ homozygotes (E3/E3), and $\varepsilon 4$ carriers (E3/E4 and E4/E4) as shown in Table 3. Owing to the probable opposing influence of the $\varepsilon 2$ and $\varepsilon 4$ alleles on lipid concentrations, individuals having E2/E4 genotype $(n=3)$ were omitted from the following analysis.

Based on the results of the ANOVA test, a significant HDL-C level was found between the three groups $(p=0.005)$. A lower HDL-C level was found in ApoE $\varepsilon 2$ carriers in comparison with $\varepsilon 3$ homozygotes: 33.25 vs. $47.37 \mathrm{mg} / \mathrm{dL}(p=0.003 ; 95 \% \mathrm{CI}-23.35-4.89)$. A lower significant level of HDL-C was also obtained in $\varepsilon 4$ carriers compared to $\varepsilon 3$ homozygotes: 39.41 vs. $47.37 \mathrm{mg} / \mathrm{dL}$ ( $p=0.019 ; 95 \%$ CI $1.38-14.55)$. The relation between the polymorphism of the ApoE gene and other determinant factors is also reported. Age, BMI, diabetes duration, sex, hypertension, or dyslipidemia were noticed to have no relationship with ApoE gene polymorphism $(p>0.05)$.

3.4. Apolipoprotein E Gene Polymorphism and Ischemic Stroke Risk in T2DM. Hypertension, smoking, high level of 2-hour plasma glucose $(\geq 140 \mathrm{mg} / \mathrm{dL})$, hypercholesterolemia $(\geq 200 \mathrm{mg} / \mathrm{dL})$, or high LDL-C level $(\geq 130 \mathrm{mg} / \mathrm{dL})$ were found to be substantially associated with IS in T2DM patients $(p<0.05)$ as shown in Table 4. After adjustment for other determinant conditions, multivariate logistic regression analysis was performed and indicated that hypertension was an independent risk factor for IS in T2DM (Table 5). Hypertension increased IS risk in T2DM patients by 5.01 folds ( $p=0.035 ; 95 \%$ CI 1.12-22.49). The $\varepsilon 4$ allele was not an IS complication risk factor in T2DM ( $p=0.060$; adjusted OR: 4.71 ; 95\% CI 0.93-23.79).

\section{Discussion}

ApoE gene polymorphism in diabetic patients with or without IS in Balinese was first reported in our study. Our study reported that the most frequent genotype and allele were E3/E3 and $\varepsilon 3$ homozygotes, respectively. We observed greater frequencies of the $\varepsilon 4$ allele in total (23.3\%) and smaller frequencies of the $\varepsilon 3$ allele $(67.5 \%)$ in the research participants in comparison with most other populations in previous articles. A study conducted in Thailand revealed greater frequencies of the non- $\varepsilon 3$ allele like the $\varepsilon 4$ allele [25]. This finding is indicated that the allelic distribution of the ApoE gene in Balinese is close to that in Thailand. Geographic distribution has a profound effect on the ApoE genotype and allele frequencies. Striking heterogeneity following a south-to-north gradient of ApoE allele frequencies was found in the European [26] and African populations [27]. The $\varepsilon 4$ allele frequency heterogeneities were also found in Japan [28] and China [29].

This study showed that ApoE gene polymorphism was associated with plasma HDL-C concentrations. Both $\varepsilon 2$ and $\varepsilon 4$ carrier status appeared to be related to lower levels of HDL-C in comparison with the most common allele $(\varepsilon 3)$. These findings were supported by earlier studies that reported that the $\varepsilon 4$ allele was associated with substantially lower plasma levels of HDL-C in the Thai population [30] and Spanish diabetic women [31]. Meta-analysis had shown that significantly smaller plasma levels of HDL-C were found in $\varepsilon 4$ carriers in comparison with $\varepsilon 3$ and $\varepsilon 2$ carriers [13]. E3/E4 genotype was also found to have a relationship with lower levels of HDL-C in the Indian population [32]. Changes in the lipoprotein expression in T2DM are influenced by insulin resistance. The rate of HDL-C degradation increases during insulin resistance, but HDL-C production is not affected, which leads to a decrease in plasma HDL-C levels [33]. 
TABle 1: Demographic, clinical, and biochemical data of the participants.

\begin{tabular}{|c|c|c|c|}
\hline Variable & T2DM + IS $(n=30)$ & T2DM $(n=30)$ & $p$ \\
\hline Age (years) & $57.3 \pm 9.63$ & $57.47 \pm 9.31$ & 0.946 \\
\hline Sex (male/female) & $17 / 13$ & $18 / 12$ & 0.793 \\
\hline BMI $\left(\mathrm{kg} / \mathrm{m}^{2}\right)$ & $25.43(22.96-27.47)$ & $25.58(23.73-28.12)$ & 0.344 \\
\hline $\mathrm{SBP}(\mathrm{mmHg})$ & $144 \pm 24.86$ & $125.67 \pm 15.69$ & $0.001^{*}$ \\
\hline DBP (mmHg) & $90(80-100)$ & $80(70-80)$ & $0.001^{*}$ \\
\hline Hypertension & $20(66.7 \%)$ & $8(26.7 \%)$ & $0.002^{*}$ \\
\hline Diabetes duration (years) & $4[2-6]$ & $3[2-5]$ & 0.688 \\
\hline Smoking & $17(56.7 \%)$ & $7(23.3 \%)$ & $0.008^{*}$ \\
\hline Dyslipidemia & $25(83.3 \%)$ & $22(73.3 \%)$ & 0.347 \\
\hline FPG $(\mathrm{mg} / \mathrm{dL})$ & $157.23 \pm 53.59$ & $160 \pm 46.85$ & 0.832 \\
\hline 2-hour plasma glucose $(\mathrm{mg} / \mathrm{dL})$ & $167.07 \pm 52.24$ & $224.33 \pm 60.14$ & $<0.001^{*}$ \\
\hline $\mathrm{HbA1C}(\mathrm{mg} / \mathrm{dL})$ & $7.2(6.5-9.2)$ & $7.55(6.8-8.8)$ & 0.583 \\
\hline $\mathrm{TC}(\mathrm{mg} / \mathrm{dL})$ & $201.5(172-252)$ & $174.5(144-202)$ & $0.027^{*}$ \\
\hline $\mathrm{TG}(\mathrm{mg} / \mathrm{dL})$ & $113(101-167)$ & $128.5(95-194)$ & 0.912 \\
\hline LDL-C (mg/dL) & $143(120-189)$ & $116(91-143)$ & $0.005^{*}$ \\
\hline HDL-C (mg/dL) & $41.17 \pm 12$ & $42.77 \pm 12.54$ & 0.616 \\
\hline
\end{tabular}

BMI: body mass index, SBP: systolic blood pressure, DBP: diastolic blood pressure, FPG: fasting plasma glucose, HbA1C: hemoglobin A1C, TC: total cholesterol, TG: triglycerides, LDL-C: low-density lipoprotein cholesterol, HDL-C: high-density lipoprotein cholesterol. *Statistically significant difference in comparison between two groups $(p<0.05)$.


FIGURE 1: Apolipoprotein E genotyping on clinical DNA samples by sequencing.

TABLE 2: Apolipoprotein E genotype and allele frequencies of subjects.

\begin{tabular}{ccc}
\hline Variable & T2DM + IS & T2DM \\
\hline Genotype & - & - \\
E2/E2 & $2(6.7 \%)$ & $6(20 \%)$ \\
E2/E3 & $2(6.7 \%)$ & $1(3.3 \%)$ \\
E2/E4 & $12(40 \%)$ & $15(50 \%)$ \\
E3/E3 & $12(40 \%)$ & $7(23.3 \%)$ \\
E3/E4 & $2(6.7 \%)$ & $1(3.3 \%)$ \\
E4/E4 & $4(6.7 \%)$ & $7(11.7 \%)$ \\
\hline Allele & $38(63.3 \%)$ & $43(71.7 \%)$ \\
$\varepsilon 2$ & $18(30 \%)$ & $10(16.7 \%)$ \\
$\varepsilon 3$ &
\end{tabular}

T2DM, type 2 diabetes mellitus; IS, ischemic stroke.

However, there were still inconsistent results from earlier studies regarding ApoE gene polymorphism's impact on other lipid parameters. Lower levels of HDL-C and also higher levels of TG were found in the CVD patients with T2DM who have $\varepsilon 4$ allele [34]. E3/E4 genotype was related to higher concentrations of TC and non-HDL-C in all research participants and greater LDL-C levels in both T2DM and CVD groups [35]. In contrast, no relationship is found between ApoE gene polymorphism and other plasma lipid parameters (TC, TG, and LDL-C) in our study. The different impacts of ApoE gene polymorphism on the lipid concentrations can be affected by ethnic and environmental factors as indicated in these findings [36, 37].

The relationship of ApoE gene polymorphism with IS risk remains controversial. The $\varepsilon 4$ allele was referred to be an important risk factor for cerebral infarction [14-16]. E3/E4 genotype and the $\varepsilon 4$ allele were related to the incidence of IS among coronary heart disease patients receiving statin therapy [38]. On the contrary, we found that ApoE allele distribution has no association with IS risk in T2DM 
TABLE 3: Association of apolipoprotein E gene polymorphism with lipid levels and other metabolic-vascular risk factors.

\begin{tabular}{lccc}
\hline Variables & $\varepsilon 2$ carriers & $\varepsilon 3$ homozygotes & $\varepsilon 4$ carriers \\
\hline Lipid profile & & & $p$ \\
TC (mg/dL) & $175(135.5-210.5)$ & $202(172.5-246.5)$ & $175.5(155-228)$ \\
TG (mg/dL) & $158(102-356.5)$ & $115(93-172.5)$ & $130(100-185)$ \\
LDL-C (mg/dL) & $101.5(79-146.5)$ & $143(119-171)$ & $120(109-161)$ \\
HDL-C (mg/dL) & $33.25 \pm 10.11^{\mathrm{a}}$ & $47.37 \pm 11.24$ & 0.423 \\
\hline Metabolic-vascular risk factors & & & 0.439 \\
Age (years) & $58.13 \pm 13.41$ & $56 \pm 8.152$ & $0.005^{*}$ \\
BMI (kg/m ${ }^{2}$ ) & $26.38 \pm 3.21$ & $25.65 \pm 2.96$ & $58.05 \pm 8.61$ \\
Diabetes duration (years) & $6 \pm 4.81$ & $3.91 \pm 3.56$ & $26.39 \pm 3.14$ \\
Sex (male/female) & $5 / 3$ & $13 / 14$ & $3.5 \pm 2.38$ \\
Hypertension (\%) & 37.5 & 51.9 & $14 / 8$ \\
Dyslipidemia (\%) & 87.5 & 77.8 & 45.5 \\
\hline
\end{tabular}

${ }^{*}$ Statistically significant difference in comparison between three groups $(p<0.05) .{ }^{a} p=0.003$ for $\varepsilon 2$ carriers vs. $\varepsilon 3$ homozygotes. ${ }^{b} p=0.019$ for $\varepsilon 4$ carriers vs. $\varepsilon 3$ homozygotes.

TABLE 4: Bivariate analysis of variables related to ischemic stroke in T2DM.

\begin{tabular}{|c|c|c|c|c|}
\hline Variables & T2DM + IS $(n=30)(\%)$ & T2DM $(n=30)(\%)$ & OR (95\% CI) & $p$ \\
\hline \multicolumn{5}{|l|}{ Hypertension } \\
\hline $\begin{array}{l}\text { Yes } \\
\text { No }\end{array}$ & $\begin{array}{l}20(71.4) \\
10(31.3)\end{array}$ & $\begin{array}{c}8(28.6) \\
22(68.8)\end{array}$ & $5.5(1.81-16.68)$ & $0.002^{*}$ \\
\hline \multicolumn{5}{|l|}{ Smoking habits } \\
\hline $\begin{array}{l}\text { Yes } \\
\text { No } \\
\end{array}$ & $\begin{array}{l}17(70.8) \\
13(36.1)\end{array}$ & $\begin{array}{c}7(29.2) \\
23(63.9)\end{array}$ & $4.3(1.41-13.07)$ & $0.008^{*}$ \\
\hline $\begin{array}{l}\text { 2-hour plasma gluc } \\
\text { High } \\
\text { Normal } \\
\end{array}$ & $\begin{array}{c}21(42.9) \\
9(81.8) \\
\end{array}$ & $\begin{array}{c}28(57.1) \\
2(18.2) \\
\end{array}$ & $0.17(0.03-0.85)$ & $0.020^{*}$ \\
\hline $\begin{array}{l}\text { TC } \\
\text { High } \\
\text { Normal } \\
\end{array}$ & $\begin{array}{l}16(66.7) \\
14(38.9) \\
\end{array}$ & $\begin{array}{c}8(33.3) \\
22(61.1) \\
\end{array}$ & $3.14(1.07-9.27)$ & $0.035^{*}$ \\
\hline $\begin{array}{l}\text { LDL-C } \\
\text { High } \\
\text { Normal } \\
\end{array}$ & $\begin{array}{l}19(65.5) \\
11(35.5) \\
\end{array}$ & $\begin{array}{l}10(34.5) \\
20(64.5)\end{array}$ & 3.46 (1.19-9.99) & $0.020^{*}$ \\
\hline $\begin{array}{l}\varepsilon 4 \text { vs. } \varepsilon 3 \text { carriers } \\
\varepsilon 4 \text { carriers } \\
\varepsilon 3 \text { homozygotes } \\
\end{array}$ & $\begin{array}{l}14(63.6) \\
12(44.4) \\
\end{array}$ & $\begin{array}{c}8(36.4) \\
15(55.6) \\
\end{array}$ & $2.19(0.69-6.93)$ & 0.181 \\
\hline
\end{tabular}

${ }^{*}$ Statistically significant difference $(p<0.05)$.

TABLE 5: Multivariate logistic regression of variables related to ischemic stroke in T2DM.

\begin{tabular}{lccc}
\hline Variables & $\begin{array}{c}\text { Adjusted } \\
\text { OR }\end{array}$ & 95\% CI & $p$ \\
\hline Hypertension & 5.01 & $1.12-22.49$ & $0.035^{*}$ \\
Smoking habits & 3.20 & $0.69-14.77$ & 0.136 \\
High 2-hour plasma glucose & 0.55 & $0.07-4.35$ & 0.574 \\
levels & 2.01 & $0.16-24.94$ & 0.585 \\
Hypercholesterolemia & 4.38 & $0.35-54.66$ & 0.251 \\
High LDL-C levels & 4.71 & $0.93-23.79$ & 0.060 \\
\hline 4 carriers vs. $\varepsilon 3$ homozygotes & & &
\end{tabular}

${ }^{*}$ Statistically significant $(p<0.05)$.

subjects. Similarly, several studies also suggested that although $\varepsilon 4$ and $\varepsilon 2$ carriers were associated with TC and TG levels, they were not associated with IS risk $(19,20)$ and patients' outcomes [39]. Our results also indicated that hypertension is the major independent risk factor for IS and has a significant impact than ApoE gene polymorphism on IS development. Blood pressure control was important for stroke progression in patients with diabetes [40].

\section{Conclusions}

This study indicates that both $\varepsilon 2$ and $\varepsilon 4$ carriers' statuses are associated with lower HDL-C levels. Unlike previous researches in other populations, we reported that there is no significant relationship between ApoE gene polymorphism and IS risk in T2DM. Additional researches are required to investigate whether genotyping of the ApoE gene is of value to screening complication progression in T2DM patients.

\section{Data Availability}

The datasets used to support the findings in this study are openly available from the corresponding author upon reasonable request. 


\section{Conflicts of Interest}

The authors declare that they have no conflicts of interest regarding the publication of this paper.

\section{Authors' Contributions}

NPTM and KS conceived the study design. MRS, IPEW, and IBKP participated in the recruitment of patients, and NNAD made genetic analysis and laboratory testing. The statistical analysis was provided by IWPSY. The manuscript was written by NPTM and KS. The final manuscript was read and accepted by all authors.

\section{Acknowledgments}

The authors acknowledge the helpful comments on the manuscript by other medical colleagues in the Faculty of Medicine, Udayana University, and the support of integrated biomedical laboratory staff of Udayana University for laboratory work. This work was supported by the Directorate General of Higher Education, Ministry of Education and Culture of the Republic of Indonesia in the PMDSU Scholarship.

\section{References}

[1] K. Kaku, "Pathophysiology of type 2 diabetes and its treatment policy," Japan Medical Association Journal, vol. 53, no. 1, pp. 43-46, 2010.

[2] P. Hossain, B. Kawar, and M. El Nahas, "Obesity and diabetes in the developing world-a growing challenge," New England Journal of Medicine, vol. 356, no. 3, pp. 213-215, 2007.

[3] M. H. Forouzanfar, A. Afshin, L. T. Alexander et al., "Global, regional, and national comparative risk assessment of 79 behavioural, environmental and occupational, and metabolic risks or clusters of risks, 1990-2015: a systematic analysis for the global burden of disease study 2015," The Lancet, vol. 388, pp. 1659-1724, 2016.

[4] J. A. Beckman and M. A. Creager, "Vascular complications of diabetes," Circulation Research, vol. 118, no. 11, pp. 1771-1785, 2016.

[5] T. Kuwashiro, H. Sugimori, T. Ago, J. Kuroda, M. Kamouchi, and T. Kitazono, "The impact of predisposing factors on longterm outcome after stroke in diabetic patients: the fukuoka stroke registry," European Journal of Neurology, vol. 20, no. 6, pp. 921-927, 2013.

[6] N. Akhtar, S. Kamran, R. Singh et al., "The impact of diabetes on outcomes after acute ischemic stroke: a prospective observational study," Journal of Stroke and Cerebrovascular Diseases, vol. 28, no. 3, pp. 619-626, 2019.

[7] X.-B. Li, A.-D. Xu, J. Wang et al., "Apolipoprotein E polymorphisms increase the risk of post-stroke depression," Neural Regeneration Research, vol. 11, no. 11, pp. 1790-1796, 2016.

[8] H. Zhang, X. Zhao, C. Wang et al., "A preliminary study of the association between apolipoprotein E promoter methylation and atherosclerotic cerebral infarction," Journal of Stroke and Cerebrovascular Diseases, vol. 28, no. 4, pp. 1056-1061, 2019.

[9] V. V. Giau, E. Bagyinszky, S. S. An, and S. Y. Kim, "Role of apolipoprotein E in neurodegenerative diseases," Neuropsychiatric Disease and Treatment, vol. 11, pp. 1723-1737, 2015.
[10] P. G. Anthopoulos, S. J. Hamodrakas, and P. G. Bagos, "Apolipoprotein E polymorphisms and type 2 diabetes: a meta-analysis of 30 studies including 5423 cases and 8197 controls," Molecular Genetics and Metabolism, vol. 100, no. 3, pp. 283-291, 2010.

[11] A. Kumar, P. Kumar, M. Prasad, S. Misra, A. Kishor Pandit, and K. Chakravarty, "Association between apolipoprotein $\varepsilon 4$ gene polymorphism and risk of ischemic stroke: a metaanalysis," Annals of Neurosciences, vol. 23, no. 2, pp. 113-121, 2016.

[12] J. E. Eichner, S. T. Dunn, G. Perveen, D. M. Thompson, K. E. Stewart, and B. C. Stroehla, "Apolipoprotein E polymorphism and cardiovascular disease: a HuGE review," American Journal of Epidemiology, vol. 155, no. 6, pp. 487495, 2002.

[13] A. M. Bennet, E. Di Angelantonio, Z. Ye et al., "Association of apolipoprotein e genotypes with lipid levels and coronary risk," Jama, vol. 298, no. 11, pp. 1300-1311, 2007.

[14] Z. Q. Jin, Y. S. Fan, J. Ding et al., "Association of apolipoprotein E 4 polymorphism with cerebral infarction in Chinese Han population," Acta Pharmacologica Sinica, vol. 25, no. 3, pp. 352-356, 2004.

[15] Q.-Y. Wang, W.-J. Wang, L. Wu, L. Liu, and L.-Z. Han, "Meta-analysis of APOE $\varepsilon 2 / \varepsilon 3 / \varepsilon 4$ polymorphism and cerebral infarction," Journal of Neural Transmission, vol. 120, no. 10, pp. 1479-1489, 2013.

[16] H.-Q. Yan, Y. Yuan, P. Zhang, Z. Huang, L. Chang, and Y.-K. Gui, "Association of the ApoE gene polymorphism and dietary factors with cerebral infarction and circulating lipid concentrations," Genetics and Molecular Research, vol. 14, no. 1, pp. 665-670, 2015.

[17] C. Chen and Z. Hu, "ApoE polymorphisms and the risk of different subtypes of stroke in the Chinese population: a comprehensive meta-analysis," Cerebrovascular Diseases, vol. 351, no. 4, pp. 380-386, 2016.

[18] J. P. Casas, A. D. Hingorani, L. E. Bautista, and P. Sharma, "Meta-analysis of genetic studies in ischemic stroke," Archives of Neurology, vol. 61, no. 11, pp. 1652-1661, 2004.

[19] J. D. Sturgeon, A. R. Folsom, M. S. Bray, E. Boerwinkle, and C. M. Ballantyne, "Apolipoprotein E genotype and incident ischemic stroke," Stroke, vol. 36, no. 11, pp. 2484-2486, 2005.

[20] G. Giassakis, S. Veletza, N. Papanas, I. Heliopoulos, and H. Piperidou, "Apolipoprotein E and first-ever ischaemic stroke in Greek hospitalized patients," Journal of International Medical Research, vol. 35, no. 1, pp. 127-133, 2007.

[21] World Health Organization, Definition and Diagnosis of Diabetes Mellitus and Intermediate Hyperglycemia, WHO, Geneva, Switzerland, 2006.

[22] E. C. Jauch, J. L. Saver, H. P. Adams et al., "Guidelines for the early management of patients with acute ischemic stroke," Stroke, vol. 44, no. 3, pp. 870-947, 2013.

[23] P. S. Jellinger, R. A. Dickey, O. P. Ganda et al., “AACE medical guidelines for clinical practice for the diagnosis and treatment of dyslipidemia and prevention of atherogenesis," Endocrine Practice, vol. 6, no. 2, pp. 162-213, 2000.

[24] A. Zivelin, N. Rosenberg, H. Peretz, Y. Amit, N. Kornbrot, and U. Seligsohn, "Improved method for genotyping apolipoprotein E polymorphisms by a PCR-based assay simultaneously utilizing two distinct restriction enzymes," Clinical Chemistry, vol. 43, no. 9, pp. 1657-1659, 1997.

[25] N. Jeenduang, S. Porntadavity, and S. Wanmasae, "Combined PCSK9 and APOE polymorphisms are genetic risk factors associated with elevated plasma lipid levels in a Thai population," Lipids, vol. 50, no. 6, pp. 543-553, 2015. 
[26] D. C. Ewbank, "The APOE gene and differences in life expectancy in europe," The Journals of Gerontology, Series A, Biological Sciences and Medical Sciences, vol. 59, no. 1, pp. 16-20, 2004.

[27] S. Saidi, L. B. Slamia, S. B. Ammou, T. Mahjoub, and W. Y. Almawi, "Association of apolipoprotein E gene polymorphism with ischemic stroke involving large-vessel disease and its relation to serum lipid levels," Journal of Stroke and Cerebrovascular Diseases, vol. 16, no. 4, pp. 160-166, 2007.

[28] L. Ulrik Gerdes, "The common polymorphism of apolipoprotein E: geographical aspects and new pathophysiological relations," Clinical Chemistry and Laboratory Medicine, vol. 41, no. 5, pp. 628-631, 2003.

[29] P. Hu, Y. H. Qin, C. X. Jing, L. Lu, B. Hu, and P. F. Du, "Does the geographical gradient of ApoE4 allele exist in China? A systemic comparison among multiple Chinese populations," Molecular Biology Reports, vol. 38, no. 1, pp. 489-494, 2011.

[30] R. Chaudhary, A. Likidlilid, T. Peerapatdit et al., "Apolipoprotein $\mathrm{E}$ gene polymorphism: effects on plasma lipids and risk of type 2 diabetes and coronary artery disease," Cardiovascular Diabetology, vol. 11, no. 1, p. 36, 2012.

[31] D. Gómez-Coronado, J. J. Álvarez, A. Entrala, J. M. Olmos, E. Herrera, and M. Á. Lasunción, "Apolipoprotein E polymorphism in men and women from a Spanish population: allele frequencies and influence on plasma lipids and apolipoproteins," Atherosclerosis, vol. 147, no. 1, pp. 167-176, 1999.

[32] P. Singh, M. Singh, D. Bhatnagar, T. Kaur, and S. Gaur, "Apolipoprotein E polymorphism and its relation to plasma lipids in coronary heart disease," Indian Journal of Medical Sciences, vol. 62, no. 3, pp. 105-112, 2008.

[33] P. Zhang, J. Gao, C. Pu, and Y. Zhang, "Apolipoprotein status in type 2 diabetes mellitus and its complications," Molecular Medicine Reports, vol. 16, no. 6, pp. 9279-9286, 2017.

[34] S. Liu, J. Liu, R. Weng, X. Gu, and Z. Zhong, "Apolipoprotein e gene polymorphism and the risk of cardiovascular disease and type 2 diabetes," BMC Cardiovascular Disorders, vol. 19, p. 213, 2019.

[35] D. El-Lebedy, H. M. Raslan, and A. M. Mohammed, "Apolipoprotein E gene polymorphism and risk of type 2 diabetes and cardiovascular disease," Cardiovascular Diabetology, vol. 15, p. 12, 2016.

[36] R. W. Mahley and S. C. Rall, "Apolipoproteine: far more than a lipid transport protein," Annual Review of Genomics and Human Genetics, vol. 1, no. 1, pp. 507-537, 2000.

[37] G. D. Kolovou and K. K. Anagnostopoulou, "Apolipoprotein E polymorphism, age and coronary heart disease," Ageing Research Reviews, vol. 6, no. 2, pp. 94-108, 2007.

[38] P. Lv, Y. Zheng, J. Huang, J. Ke, and H. Zhang, "Association of apolipoprotein $\mathrm{E}$ gene polymorphism with ischemic stroke in coronary heart disease patients treated with medium-intensity statins," Neuropsychiatric Disease and Treatment, vol. 16, pp. 2459-2466, 2020.

[39] Y. Zhang, S. Liu, W. Yue et al., "Association of apolipoprotein e genotype with outcome in hospitalized ischemic stroke patients," Medicine, vol. 96, no. 50, Article ID e8964, 2017.

[40] G. Reboldi, G. Gentile, F. Angeli, G. Ambrosio, G. Mancia, and P. Verdecchia, "Effects of intensive blood pressure reduction on myocardial infarction and stroke in diabetes: a meta-analysis in 73913 patients," Journal of Hypertension, vol. 29, no. 7, pp. 1253-1269, 2011. 